\title{
Erratum zu: Statistische Tests mit Excel leicht erklärt Wolf-Gert Matthäus
}

Der Buchtitel und der Name des Autors wurden in allen Kapiteln dieses Buches falsch erfasst. Der korrekte Titel sollte "Statistische Tests mit Excel leicht erklärt" sein und der korrekte Autorenname sollte Wolf-Gert Matthäus sein. Dies wurde korrigiert.

Die aktualisierte Online-Version des Originalbuchs finden Sie unter https://doi.org/10.1007/978-3-8351-9111-2.

(C) B.G. Teubner Verlag / GWV Fachverlage GmbH, Wiesbaden, 2021

W-G. Matthäus, Statistische Tests mit Excel leicht erklärt,

DOI 10.1007/978-3-8351-9111-2_19 